\begin{tabular}{|c|c|c|c|}
\hline Reports & \multicolumn{2}{|c|}{ Case Rep Gastroenterol 2016;10:88-94 } & \multirow[b]{2}{*}{$\begin{array}{l}\text { Karger } \\
\text { Open access }\end{array}$} \\
\hline Gastr & $\begin{array}{l}\text { DOI: 10.1159/000444442 } \\
\text { Publisned onlıne: IVlay 19, } 2016\end{array}$ & $\begin{array}{l}\text { (C) } 2016 \text { The Author(s) } \\
\text { Published by S. Karger AG, Basel } \\
\text { www.karger.com/crg }\end{array}$ & \\
\hline & \multicolumn{3}{|c|}{$\begin{array}{l}\text { This article is licensed under the Creative Commons Attribution-NonCommercial } 4.0 \\
\text { International License (CC BY-NC) (http://www.karger.com/Services/OpenAccessLicense). } \\
\text { Usage and distribution for commercial purposes requires written permission. }\end{array}$} \\
\hline
\end{tabular}

\title{
Two Cases of Paradoxical Hidradenitis Suppurativa while on Adalimumab
}

\author{
Glenn Harvin George Kasarala \\ Department of Gastroenterology, Hepatology and Nutrition, Brody School of Medicine at \\ East Carolina University, Greenville, N.C., USA
}

\section{Keywords}

Hidradenitis Suppurativa · Adalimumab · Crohn's disease

\begin{abstract}
Hidradenitis suppurativa (HS) is a chronic, inflammatory skin disease characterized by recurring abscesses, nodules, and fistulas predominantly in the groin and axillae. The association between HS and Crohn's disease (CD) has been well documented. Tumor necrosis factor (TNF) inhibitors have shown to be effective in treating both HS and CD. We report 2 patients who developed HS while on TNF inhibitor treatment for CD.

(C) 2016 The Author(s)

Published by S. Karger AG, Basel
\end{abstract}

\section{Introduction}

Crohn's disease (CD) is an idiopathic chronic inflammatory bowel disease that can affect any part of the gastrointestinal tract. Hidradenitis suppurativa (HS) is a chronic inflammatory skin disease characterized by recurrent deep, painful nodules, often of the axilla, groin and gluteal areas, that can lead to abscesses and chronic draining sinus tracts [1]. The association between HS and CD is well documented [2]. Patients with inflammatory bowel disease were approximately nine times more likely to develop HS than the general population in a population-based cohort study [3]. Tumor necrosis factor (TNF) inhibitors have been shown to be effective in treating recalcitrant HS [4] and moderate to severe CD. [5] Paradox- 


\section{Case Reports in Gastroenterology}

Case Rep Gastroenterol 2016;10:88-94

(c) 2016 The Author(s). Published by S. Karger AG, Basel www.karger.com/crg

Harvin and Kasarala: Two Cases of Paradoxical Hidradenitis Suppurativa while on Adalimumab

ical psoriatic skin lesions while on anti-TNF therapy have also been well described [6]. We present 2 patients who developed HS while receiving treatment with adalimumab for CD. We describe some of the immunologic similarities between HS and the psoriasiform rash that has been noted on anti-TNF therapy, and explain why HS should be considered as one of the rare skin rashes that can develop while a patient is on anti-TNF therapy.

\section{Case 1}

A 57-year-old African American female presented to our emergency department with a 6-month history of diarrhea, urgency and tenesmus. She was found to have a perirectal abscess. CT of the abdomen was significant for thickening of the rectum and sigmoid colon. On rectal examination, she was noted to have an anal fistula. The perirectal abscess was drained, and a seton was placed for the anal fistula. A colonoscopy was performed showing erythema and friability consistent with colitis extending to the transverse colon, although most pronounced in the sigmoid colon and rectum. The remainder of the colon and the terminal ileum were normal. Biopsies from the involved portion of the colon including the rectum showed acute cryptitis with crypt abscess formation and crypt distortion and were consistent with CD. The patient was started on adalimumab and mesalamine suppositories with significant clinical improvement. A follow-up sigmoidoscopy after 8 months showed resolution of the colitis with only mild proctitis remaining. The patient continues to smoke despite counseling.

Twelve months into treatment, she developed recurrent boils and nodules in her groin. Her white blood cell count was normal $(6,900 / \mu \mathrm{l})$. She was started on amoxicillin $875 \mathrm{mg}$ and clavulanic acid $125 \mathrm{mg}$ orally twice a day for 10 days. With the suspicion of HS, she was referred to the dermatology clinic, and the diagnosis was confirmed. Her skin lesions improved only transiently on the antibiotics. Her disease progressed with multiple boils and draining sinus tracts in her groin bilaterally with involvement of her right posterior thigh (fig. 1, HS of the right posterior thigh; fig. 2, HS of the left groin) but no axillary involvement. She had no prior history of HS or psoriasis. She was started on doxycycline $100 \mathrm{mg}$ orally twice a day for 10 days and subsequently also with 10-day courses of cephalexin followed by clindamycin with minimal improvement. She was started on suppressive therapy with doxycycline $100 \mathrm{mg}$ orally twice a day for 2 months with some improvement. She was transitioned off the antibiotics but the disease recurred. She was treated with several additional 10-day courses of amoxicillin/clavulanic acid followed by clindamycin. She was placed back on suppressive therapy with doxycycline $100 \mathrm{mg}$ orally twice a day for the next 3 months followed by minocycline for one month. Over the past 2 years, she received intralesional triamcinolone injections on five occasions with little improvement. Currently, she is being evaluated by plastic surgery for surgical excision.

Thirty months into treatment, the patient developed erythematous scaly plaques on her back (fig. 3) and at the site of adalimumab injections (fig. 4) and was diagnosed with psoriasis. Meanwhile, her CD was well controlled on adalimumab with mild disease confined to the rectum with no new fistula formation. It was believed that the adalimumab was causing the HS, and the drug was discontinued despite good control of her CD. The patient was switched to azathioprine. 


\section{Case 2}

A 24 year-old African American male non-smoker presented to the emergency room with a 1-year history of intermittent bright red blood per rectum with no associated abdominal pain or tenesmus. A colonoscopy was performed showing erythema and friability from the rectum to the descending colon. The biopsies showed chronic colitis with granulomas consistent with Crohn's colitis. He was started on oral Lialda $2.4 \mathrm{~g}$ daily, but the disease progressed with worsening abdominal pain, diarrhea and the development of an anal fistula. Therapy was changed to adalimumab for moderate-severe CD. Nine months into adalimumab therapy, he developed a right groin abscess with spontaneous drainage. Initially, it was thought that this was folliculitis, and he was treated with Bactrim for 2 weeks. He went on to develop multiple nodules in his groin bilaterally with the development of draining sinuses but no axillary lesions. He was diagnosed with HS; he had no personal or family history of HS. He was treated by dermatology with several 10- to 14-day courses of Bactrim and amoxicillin $875 \mathrm{mg} /$ clavulanic acid $125 \mathrm{mg}$ separately with transient improvement. He also had surgical excision of these areas and was started on chronic suppressive therapy with doxycycline $100 \mathrm{mg}$ orally twice a day. On follow-up, his CD was not well controlled with worsening anal fistula, and azathioprine was added to adalimumab. HS also progressed to involve his axillary region.

\section{Discussion}

The association of CD with HS has been determined [2], and TNF antagonists to include infliximab have been shown to be helpful in treating patients with CD and HS [2, 7]. TNF plays an important role in both CD and HS [7]. CD is characterized by the predominance of increased T helper 1 (Th1) lymphocytes with Th17 cytokine expression [8]. TNF antagonists such as infliximab and adalimumab have been used to treat diseases such as $\mathrm{CD}$, ulcerative colitis and psoriasis.

Recent studies have implicated anti-TNF antibodies as a cause of psoriasiform skin lesions in a small subset of patients with inflammatory bowel disease treated with these agents. Historically, this risk has been believed to be very small. However, several studies have indicated a higher risk than previously thought. In a recent study of 434 anti-TNF treated patients with inflammatory bowel disease, $4.8 \%$ developed psoriasiform skin lesions [9]. Smoking has been shown to be a risk factor for anti-TNF-induced skin lesions [9]. In the study by Tillack et al., $76 \%$ of the patients that developed psoriasiform skin lesions on antiTNF were smokers or ex-smokers [9]. The skin lesions developed on average 13 months after initiation of the drug in multiple studies $[6,10]$, and most of the cases were confined to the palmoplantar and scalp areas [10]. In many cases, the drug had to be withdrawn due to the rash (43\% in the study by Cullen et al. [11]). The psoriasiform rash is believed to be likely a class effect. Of the patients switched to an alternative anti-TNF in the review by Cullen et al. [11], 52\% were unable to continue the drug due to recurrence of the rash, and only $15 \%$ were successful in controlling the rash by switching to an alternative anti-TNF.

In normal skin, TNF- $\alpha$ acts to inhibit the overproduction of interferon- $\gamma$ [10]. It has been theorized that anti-TNF drugs allow unopposed interferon $-\gamma$ production leading to activation of T helper cells producing IL-17 [10]. Increased concentrations of IL-17A and IL-23 have been shown in CD patients who developed skin lesions while on anti-TNF- $\alpha$ therapy [12]. It has also been shown that anti-TNF-induced psoriasiform skin lesions have infiltrates 
of Th17 and Th1 cells, which are similar to the cytokine profile of psoriasis [9], and as noted below are similar to the profiles seen in HS. It is believed that the TNF blockade may cause the disruption of the cytokine balance in patients with psoriasiform skin lesions leading to unopposed interferon- $\alpha$ production by plasmacytoid dendritic cells in these genetically predisposed patients [13].

Studies have highlighted skin lesions such as psoriasiform lesions and eczema that can develop on ant-TNF therapy, but there is no mention of HS $[6,10,12]$. There was a recent case series of several patients that developed HS during treatment with adalimumab [14]. This is interesting, as adalimumab has been shown to be effective in treating HS in some small studies [4], though not all [15]. There was a range of several weeks to 24 months to the onset or exacerbation of HS after starting adalimumab in this series [14]. Two of the 4 patients in this series did have CD. The development of HS has also been described on etanercept [16]. Also, in a study looking at adalimumab for treatment of HS, $40 \%$ of the patients withdrew due to worsening of HS [15]. Due to very few reported cases of HS developing while on anti-TNF therapy, a conclusion as to whether this is a class effect of TNF antagonists cannot be determined. However, the occurrence of anti-TNF-induced psoriasiform lesions is believed to be a class effect [9], and this opens up the possibility that anti-TNF-induced HS might also be a class effect.

In the case series by Delobeau et al., 3 of the 4 patients were able to continue on the antiTNF, while 1 patient required a switch to ustekinumab [14]. One of the 2 patients in our series had to be switched to another agent due to poorly controlled HS despite multiple therapeutic agents. This is only the second case in which we are aware of the development of HS associated with psoriasis [14]. Our series and the series by Delobeau et al. are unique in that the patients developed HS while already on adalimumab rather than being started as a potential treatment for HS.

Increased concentrations of TNF- $\alpha$ has been seen in the serum of patients with HS [17] and in HS skin [18]. Adalimumab treatment has been shown to cause a large reduction in the number of $\mathrm{CD} 11 \mathrm{c}^{+}$dendritic cells which are involved in HS pathophysiology [18]. Abundant expression of IL-12 and IL-23 was seen in the lesional skin of patients with HS [19]. IL-23 has an important role in Th17 development, and Th17 cells were seen to infiltrate the lesional skin in a study of HS patients [19].

The cytokine profiles of HS, psoriasis and anti-TNF induced psoriasiform lesions as noted above are very similar. This opens the possibility that like psoriasis, HS is a rare skin lesion that can develop while on anti-TNF therapy and is perhaps due to a cytokine dysregulation as has been seen with TNF antagonists and psoriasiform skin lesions. Ustekinumab is an anti-IL-12/IL-23 antibody, which has been used for anti-TNF-induced psoriasiform skin lesions [9] and has shown some benefit in CD [20]. This opens the way for a possible use of Ustekinumab to treat both CD and HS.

In conclusion, HS should be considered as a potential rare paradoxical side effect of antiTNF therapy.

\section{Statement of Ethics}

The authors have no ethical conflicts to disclose. 


\section{Case Reports in \\ Gastroenterology}

\begin{tabular}{l|l}
\hline $10.1159 / 000444442$ & $\begin{array}{l}\text { (c) } 2016 \text { The Author(s). Published by S. Karger AG, Basel } \\
\text { www.karger.com/crg }\end{array}$ \\
\hline
\end{tabular}

Harvin and Kasarala: Two Cases of Paradoxical Hidradenitis Suppurativa while on Adalimumab

\section{Disclosure Statement}

There are no conflicts of interest for either author.

\section{References}

1 Danby FW, Margesson LJ: Hidradenitis suppurativa. Dermatol Clin 2010;28:779-793.

2 Kamal N, Cohen BL, Buche S, Delaporte E, Colombel JF: Features of patients with Crohn's disease and hidradenitis suppurativa. Clin Gastroenterol Hepatol 2016;14:71-79.

-3 Yadav S, Singh S, Edakkanambeth Varayil J, et al: Hidradenitis suppurativa in patients with inflammatory bowel disease: a population-based cohort study in Olmsted County, Minnesota. Clin Gastroenterol Hepatol 2016;14:65-70.

4 Kimball AB, Kerdel F, Adams D, et al: Adalimumab for the treatment of moderate to severe Hidradenitis suppurativa: a parallel randomized trial. Ann Intern Med 2012;157:846-855.

-5 Hanauer SB, Sandborn WJ, Rutgeerts P, et al: Human anti-tumor necrosis factor monoclonal antibody (adalimumab) in Crohn's disease: the CLASSIC-I trial. Gastroenterology 2006;130:323-333; quiz 591.

-6 Denadai R, Teixeira FV, Steinwurz F, Romiti R, Saad-Hossne R: Induction or exacerbation of psoriatic lesions during anti-TNF- $\alpha$ therapy for inflammatory bowel disease: a systematic literature review based on 222 cases. J Crohns Colitis 2013;7:517-524.

-7 Blazquez I, Gonzalez-Lama Y, Roustan G: Crohn's disease and hidradenitis suppurativa. An uncommon association that responds to infliximab. J Crohns Colitis 2013;7:e717-e718.

8 Caprioli F, Pallone F, Monteleone G: Th17 immune response in IBD: a new pathogenic mechanism. J Crohns Colitis 2008;2:291-295.

-9 Tillack C, Ehmann LM, Friedrich M, et al: Anti-TNF antibody-induced psoriasiform skin lesions in patients with inflammatory bowel disease are characterised by interferon-gamma-expressing Th1 cells and IL-17A/IL-22-expressing Th17 cells and respond to anti-IL-12/IL-23 antibody treatment. Gut 2014;63:567-577.

10 George LA, Gadani A, Cross RK, Jambaulikar G, Ghazi LJ: Psoriasiform Skin lesions are caused by antiTNF agents used for the treatment of inflammatory bowel disease. Dig Dis Sci 2015;60:3424-3430.

11 Cullen G, Kroshinsky D, Cheifetz AS, Korzenik JR: Psoriasis associated with anti-tumour necrosis factor therapy in inflammatory bowel disease: a new series and a review of 120 cases from the literature. Aliment Pharmacol Ther 2011;34:1318-1327.

12 Wlodarczyk M, Sobolewska A, Wojcik B, Loga K, Fichna J, Wisniewska-Jarosinska M: Correlations between skin lesions induced by anti-tumor necrosis factor-alpha and selected cytokines in Crohn's disease patients. World J Gastroenterol 2014;20:7019-7026.

13 Collamer AN, Battafarano DF: Psoriatic skin lesions induced by tumor necrosis factor antagonist therapy: clinical features and possible immunopathogenesis. Semin Arthritis Rheum 2010;40:233-240.

14 Delobeau M, Abdou A, Puzenat E, et al: Observational case series on adalimumab-induced paradoxical hidradenitis suppurativa. J Dermatolog Treat 2015, Epub ahead of print.

15 Amano M, Grant A, Kerdel FA: A prospective open-label clinical trial of adalimumab for the treatment of hidradenitis suppurativa. Int J Dermatol 2010;49:950-955.

16 Pellegrino M, Taddeucci P, Peccianti C, Mei S, Fioravanti A, Fimiani M: Etanercept induced hidradenitis suppurativa. G Ital Dermatol Venereol 2011;146:503-504.

-17 Matusiak L, Bieniek A, Szepietowski JC: Increased serum tumour necrosis factor-alpha in hidradenitis suppurativa patients: is there a basis for treatment with anti-tumour necrosis factor-alpha agents? Acta Derm Venereol 2009;89:601-603.

18 van der Zee HH, Laman JD, de Ruiter L, Dik WA, Prens EP: Adalimumab (antitumour necrosis factoralpha) treatment of hidradenitis suppurativa ameliorates skin inflammation: an in situ and ex vivo study. Br J Dermatol 2012;166:298-305.

19 Schlapbach C, Hanni T, Yawalkar N, Hunger RE: Expression of the IL-23/Th17 pathway in lesions of hidradenitis suppurativa. J Am Acad Dermatol 2011;65:790-798.

20 Wils P, Bouhnik Y, Michetti P, et al: Subcutaneous ustekinumab provides clinical benefit for two-thirds of patients with Crohn's disease refractory to anti-tumor necrosis factor agents. Clin Gastroenterol Hepatol 2016;14:242-250.e2. 


\begin{tabular}{|c|c|c|}
\hline \multirow{2}{*}{$\begin{array}{l}\text { Case Reports in } \\
\text { Gastroenterology }\end{array}$} & \multicolumn{2}{|c|}{ Case Rep Gastroenterol 2016;10:88-94 } \\
\hline & $10.1159 / 000444442$ & $\begin{array}{l}\text { (c) } 2016 \text { The Author(s). Published by S. Karger AG, Basel } \\
\text { www.karger.com/crg }\end{array}$ \\
\hline
\end{tabular}

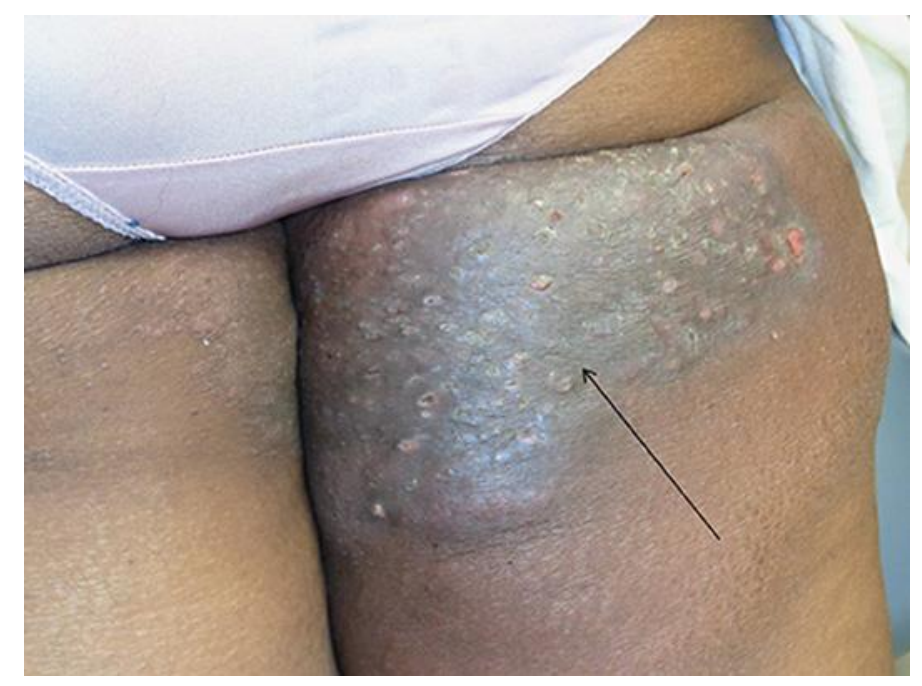

Fig. 1. HS of the posterior thigh.

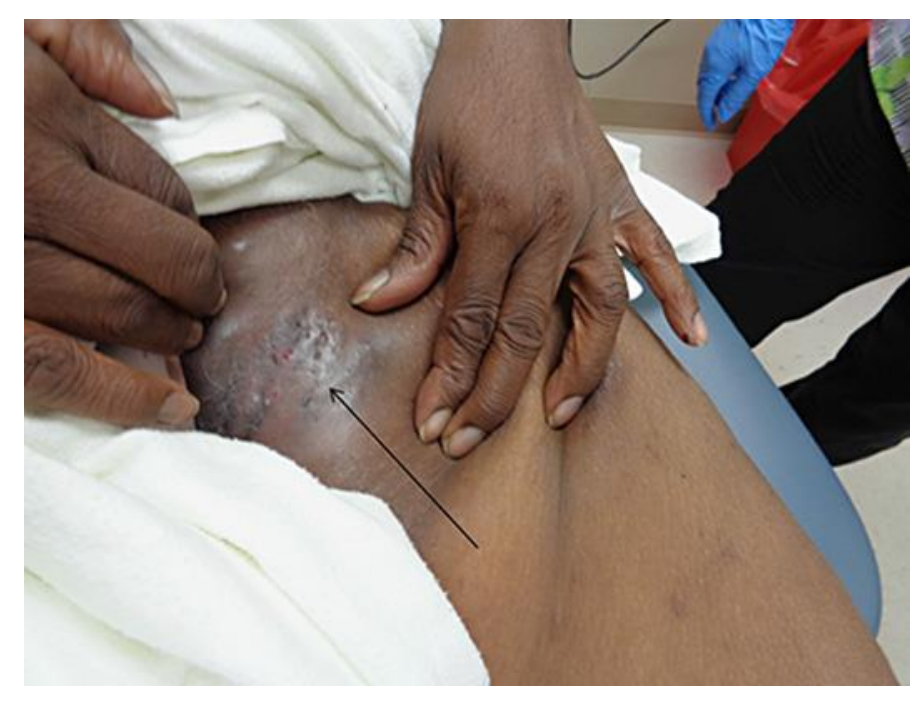

Fig. 2. HS of the left groin. 


\section{Case Reports in Case Rep Gastroenterol 2016;10:88-94 \\ (c) 2016 The Author(s). Published by S. Karger AG, Basel www.karger.com/crg \\ Harvin and Kasarala: Two Cases of Paradoxical Hidradenitis Suppurativa while on Adalimumab}

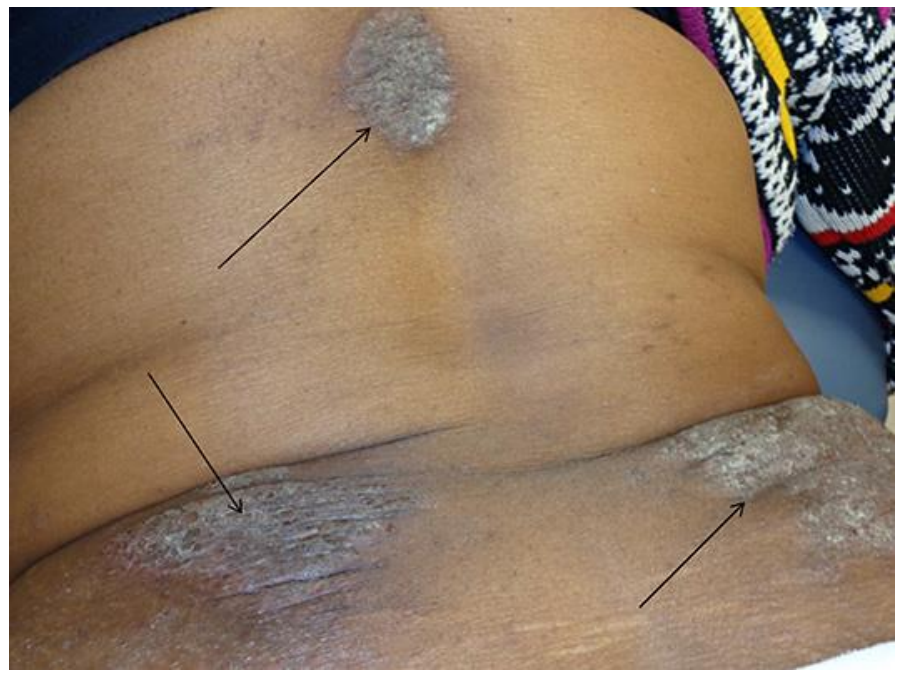

Fig. 3. Psoriasiform rash that developed on her back.

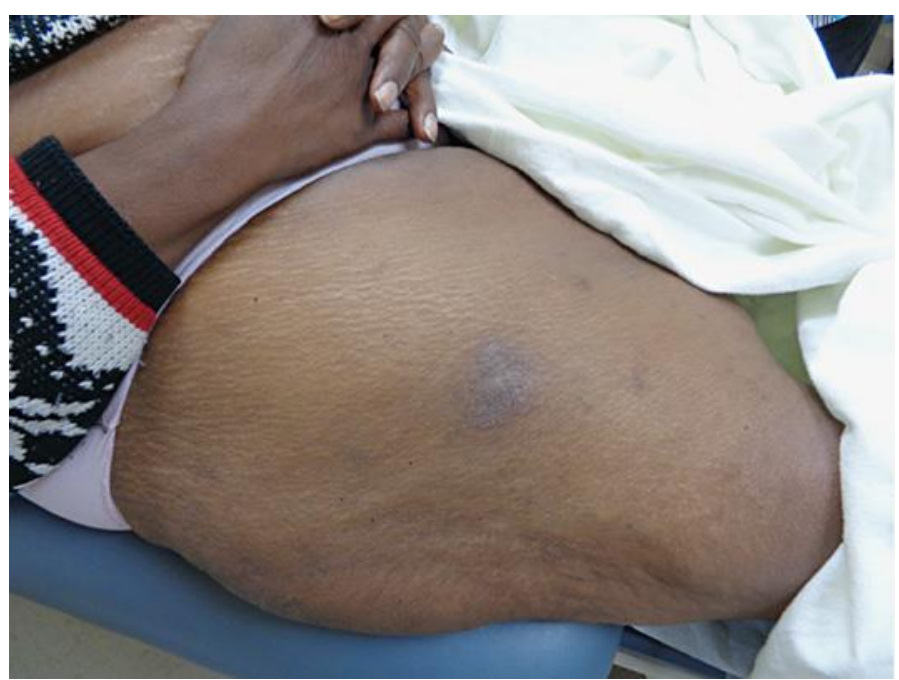

Fig. 4. Psoriasiform skin lesion at the adalimumab injection site. 